\title{
CHEMICAL COMPOSITION AND ANTIOXIDANT ACTIVITY OF CHAENOMELES MAULEI FRUIT JUICE
}

\author{
Stefka V. Valcheva-Kuzmanova, \\ Petko N. Denev ${ }^{1}$, \\ Manol H. Ognyanov ${ }^{1}$
}

Department of Pharmacology and Clinical Pharmacology and Therapeutics, Medical University - Varna, Bulgaria

${ }^{1}$ Laboratory of Biologically Active

Substances,

Institute of Organic Chemistry with

Centre of Phytochemistry, Bulgarian Academy of Sciences, Plovdiv, Bulgaria

\section{Corresponding Author:}

Stefka V. Valcheva-Kuzmanova, Department of Pharmacology and Clinical Pharmacology and Therapeutics, Medical University - Varna 55, Marin Drinov Str.

Varna, 9002

Bulgaria

e-mail address: stefkavk@yahoo.com

Received: January 30, 2018

Revision received: February 22, 2018

Accepted: June 26, 2018

\section{Summary}

Chaenomeles maulei is the name of the cultivar of Chaenomeles japonica, which was introduced in Europe. The present study aimed to investigate the chemical composition and the antioxidant activity of Chaenomeles maulei fruit juice (CMFJ). The ingredients of the juice sample were measured by spectrophotometric, high-performance liquid chromatography (HPLC) and gravimetric methods. The antioxidant activity was measured by the oxygen radical absorbance capacity (ORAC) and hydroxyl radical averting capacity (HORAC) assays. The results showed that CMFJ was extremely rich in polyphenolic substances, amongst which the highest was the concentration of procyanidin oligomers, followed by phenolic acids (vanillic $>$ caffeic $>$ chlorogenic $>$ neochlorogenic $>$ p-coumaric $>$ ellagic $>$ ferulic $>4$-dihydroxy-benzoic) and flavonoids (epicatechin $>$ catechin $>$ quercetin-3- $\beta$-glucoside $>$ quercetin $>$ rutin $>$ naringin $>$ kaempferol $>$ myricetin). The sour taste of the juice and its low $\mathrm{pH}$ were due to the high content of organic acids (malic $>$ quinic $>$ citric $>$ shikimic $>$ ascorbic $>$ oxalic). The carbohydrates were presented by glucose $>$ fructose $>$ galactose $>$ xylose $>$ rhamnose $>$ arabinose. The antioxidant activity measured by ORAC and HORAC was very high. It could be attributed to the high content of polyphenolics in the juice.

Key words: Chaenomeles maulei fruit juice, chemical composition, polyphenolic substances, organic acids, antioxidant activity

\section{Introduction}

The genus Chaenomeles belongs to the Rosaceae family and comprises four species: $C$. cathayensis, $C$. japonica, C. speciosa and C. thibetica [1]. C. japonica, known as Maule's quince or Japanese quince, was introduced to Europe in 1869 by Messrs Maule, nursery workers in Bristol, England. Chaenomeles maulei is the name of the cultivar introduced by the Maules in Europe, and the full scientific name is Chaenomeles japonica (Thunb.) Lindl [2].

Chaenomeles maulei is a dwarf shrub (0.6-1.2 $\mathrm{m})$. Because of the beautiful flowers, it has long been appreciated for its ornamental value. Due to the high yield of fruits, Chaenomeles maulei is currently being developed as a fruit crop in Europe with importance for 
food industry [3]. The valuable properties of the fruits are the distinctive aroma, the high contents of organic acids, vitamin $\mathrm{C}$, phenolic compounds and dietary fiber [3-5]. Quince fruits are used for the production of juice, syrups, liqueurs, salad dressings, carbonated soft drinks, puree and jam in China [6], the Baltic States [7] and some other countries including Bulgaria.

In recent years, the scientific interest to Chaenomeles species has been increasing. Experimental studies have investigated the beneficial effects of the plant. The fruits have been shown to possess antioxidant, antimicrobial, anti-inflammatory, cytotoxic and anti-metastatic activities [6, 8-10].

The study aimed to investigate the chemical composition and in vitro antioxidant activity of Chaenomeles maulei fruit juice (CMFJ).

\section{Materials and Methods}

\section{Chaenomeles maulei fruit juice (CMFJ)}

Chaenomeles maulei was grown in the Balkan Mountains, Bulgaria, in the region of Troyan. After handpicking, the fresh fruits were ground, crushed and squeezed. The juice was filtered, preserved with potassium sorbate $(1.0 \mathrm{~g} / \mathrm{l})$ and stored at $0{ }^{\circ} \mathrm{C}$ till the analyses.

\section{Determination of total phenols}

The spectrophotometric Folin-Ciocalteu assay was used to determine the total content of phenolic compounds [11]. Absorbance was read at $760 \mathrm{~nm}$. Gallic acid was used as a standard. The results are presented as $\mathrm{mg}$ gallic acid equivalents per liter of juice (mg GAE/l).

\section{Total proanthocyanidin content determination}

Total proanthocyanidin content was determined by the method of Sarneckis et al. (2006) [12]. Methyl cellulose solution $(0.04 \%, 1 \mathrm{ml})$ was added to properly diluted juice $(0.5 \mathrm{ml})$ and the mixture was stirred several times. Saturated ammonium sulfate solution $(1 \mathrm{ml})$ was added to this mixture and the total volume was made up to $5 \mathrm{ml}$ with deionized water. The solution was allowed to stand for $10 \mathrm{~min}$ at room temperature and then centrifuged for $5 \mathrm{~min}$ at $4000 \mathrm{x} g$. The absorbance of the solution was recorded at $280 \mathrm{~nm}$. Total proanthocyanidin content was calculated from a calibration curve with catechin solutions and was expressed as catechin equivalent per liter of juice (mg CE/l).

\section{HPLC determination of procyanidin oligomers, phenolic acids, and flavonoids}

High-performance liquid chromatography (HPLC) analyses were performed using an Agilent 1220 HPLC system (Agilent Technology, Palo Alto, Ca), equipped with a binary pump and $\mathrm{UV}-\mathrm{V}$ is detector. A wavelength of $280 \mathrm{~nm}$ was used. Phenolics separation was performed using Agilent TC-C18 column (5 Mm, $4.6 \mathrm{~mm}$ x 250 $\mathrm{mm})$ at $25^{\circ} \mathrm{C}$. Mobile phases constituted of $0.5 \%$ acetic acid (A) and 100\% acetonitrile (B) at a flow rate of $0.8 \mathrm{ml} / \mathrm{min}$. The gradient condition started with $14 \% \mathrm{~B}$, between $6 \mathrm{~min}$ and $30 \mathrm{~min}$ linearly increased to $25 \% \mathrm{~B}$, then to $50 \% \mathrm{~B}$ at $40 \mathrm{~min}$.

\section{HPLC determination of organic acids} HPLC determination of organic acids was performed using the same HPLC system. A wavelength of $210 \mathrm{~nm}$ was used. Organic acids separation was achieved using Agilent TC-C18 column $(5 \mu \mathrm{m}, 4.6 \mathrm{~mm} \times 250 \mathrm{~mm})$ at $25^{\circ} \mathrm{C}$. The mobile phase was $25 \mathrm{mM}$ phosphate $\left(\mathrm{K}_{2} \mathrm{HPO}_{4} /\right.$ $\mathrm{H}_{3} \mathrm{PO}_{4}$ ) buffer ( $\mathrm{pH} \mathrm{2.4)} \mathrm{flowing} \mathrm{at} 0.8 \mathrm{ml} / \mathrm{min}$.

\section{HPLC analysis of carbohydrates}

Samples were centrifuged (6 $000 \mathrm{x} g)$ and the supernatants were used for HPLC analysis of sugars. HPLC determination was performed on Waters 484 system, connected to a refractometric Waters R401 detector and Aminex HPX $-87 \mathrm{H}$ column (300 x $7.8 \mathrm{~mm}$, BioRad). The eluent was $0.004 \mathrm{~mol} / 1 \mathrm{sulfuric}$ acid at a flow rate of $0.5 \mathrm{ml} /$ min and temperature $23{ }^{\circ} \mathrm{C}$.

\section{Isolation of pectic polysaccharides}

CMFJ was vacuum-concentrated and filtrated through Büchner funnel. Further, one volume of the concentrated juice was mixed with two volumes of cold $96 \%$ ethanol and left overnight in a refrigerator. Then the mixture was filtered through a paper filter and the content of pectic polysaccharide was determined gravimetrically by weighing the precipitated polysaccharide on the filter. 


\section{Oxygen radical absorbance capacity (ORAC) assay}

ORAC was determined using the method developed by $\mathrm{Ou}$ et al. (2001) [13] with some modifications described in details by Denev et al. (2010) [14]. This method measures the ability of an antioxidant to neutralize peroxyl radicals. The free radical damage to fluorescein results in a downward change of fluorescent intensity. The presence of a radical scavenger results in an inhibition of the free radical damage to fluorescein resulting in a preservation of the fluorescent signal. The concentration of an antioxidant in the sample is proportional to the area under the fluorescence decay curve. Peroxyl radicals are generated by thermal decomposition of 2,2'-azobis (2-amidinopropane) dihydrochloride. Trolox solutions are used to construct a standard curve. An ORAC unit is the area under the fluorescence decay curve of a Trolox solution with a concentration of $1 \mu \mathrm{M}$. Our results are expressed in $\mu$ mol Trolox equivalents per liter ( $\mu \mathrm{mol} \mathrm{TE} / \mathrm{l})$. Measurements were performed on the FLUOstar OPTIMA Fluorometer (BMG LABTECH, Offenburg, Germany). An excitation wavelength of $485 \mathrm{~nm}$ and an emission wavelength of $520 \mathrm{~nm}$ were used.

\section{Hydroxyl radical averting capacity (HORAC)}

The method was developed by Ou et al. (2002) [15]. It measures the complexing ability of an antioxidant under Fenton reaction conditions induced by the interaction between Co (II) and hydrogen peroxide $\left(\mathrm{H}_{2} \mathrm{O}_{2}\right)$. The method is based on the oxidation of fluorescein from hydroxyl radicals generated by $\mathrm{H}_{2} \mathrm{O}_{2}$ as a result of which fluorescence decreases over time. Antioxidants block this oxidation of fluorescein. The area under the fluorescence decay curve is used to determine the antioxidant activity of the sample. Gallic acid solutions are used to construct a standard curve. The area under the fluorescence decay curve of a one $\mu \mathrm{M}$ gallic acid solution is considered as one HORAC unit. The results are expressed in $\mu \mathrm{mol}$ of gallic acid equivalents per liter ( $\mu \mathrm{mol}$ GAE/l). Measurements were performed on the FLUOstar OPTIMA Fluorimeter (BMG LABTECH, Offenburg, Germany). An excitation wavelength of $485 \mathrm{~nm}$ and an emission wavelength of 520 nm were used.

\section{Results}

\section{Chemical composition of CMFJ}

The spectrophotometric Folin-Ciocalteu assay showed that the total content of phenolic substances was extremely high $-890.00 \mathrm{mg}$ GAE/l (Table 1).

The HPLC analysis revealed a very high content of procyanidin oligomers and also the presence of several phenolic acids and flavonoids in CMFJ (Figure 1).

3 - $\beta$-glucoside, quercetin, rutin and naringin. The least was the contents of kaempferol and myricetin (Table 1).

In CMFJ, six organic acids were detected (Table 2). The highest was the content of malic acid followed by quinic acid. Lower were the contents of citric acid, shikimic acid, ascorbic acid and oxalic acid.

The phenolic acids were presented by eight acids. The highest was the content of vanillic acid, followed by caffeic acid and chlorogenic acid. Lower were the contents of neochlorogenic acid, p-coumaric acid, ellagic acid, ferulic acid and 4-dihydroxy-benzoic acid (Table 1).

The most abundant flavonoids in CMFJ were epicatechin and catechin, followed by quercetin3 - $\beta$-glucoside, quercetin, rutin and naringin. The least was the contents of kaempferol and myricetin (Table 1).

In CMFJ, six organic acids were detected (Table 2). The highest was the content of malic acid followed by quinic acid. Lower were the contents of citric acid, shikimic acid, ascorbic acid and oxalic acid.

Seven monosaccharides were detected and measured as seen from the chromatogram on Figure 2 glucose, fructose, galactose, sucrose, xylose, rhamnose and arabinose.

Amongst them, the highest was the content of glucose, followed by fructose. Considerably lower were the contents of the other monosaccharides: galactose, sucrose, xylose, rhamnose and arabinose. There was also one unidentified disaccharide. The search for polysaccharides in CMFJ did not detect such (Table 3). 
Table 1. Contents of phenolic substances in Chaenomeles maulei fruit juice; catechin equivalents (CE), gallic acid equivalents (GAE)

\begin{tabular}{ll}
\hline Phenolic substances & Content $\mathbf{( m g} / \mathbf{1 0 0} \mathbf{~ m l})$ \\
\hline Total phenols & $890.00 \mathrm{GAE}$ \\
\hline Total proanthocyanidins & 253.29 \\
\hline Procyanidin oligomers & $280.52 \mathrm{CE}$ \\
\hline Phenolic acids & \\
Vanillic acid & 14.91 \\
Caffeic acid & 14.48 \\
Chlorogenic acid & 11.00 \\
Neochlorogenic acid & 2.44 \\
p-Coumaric acid & 1.52 \\
Ellagic acid & 1.29 \\
Ferullc acid & 1.26 \\
4-dihydroxy-benzoic acid & 1.23 \\
\hline Flavonoids & \\
Epicatechin & 5.59 \\
Catechin & 5.25 \\
Quercetin-3- $\beta$-glucoside & 3.58 \\
Quercetin & 3.43 \\
Rutin & 2.72 \\
Naringin & 1.46 \\
Kaempferol & 0.42 \\
Myrecetin & 0.23 \\
\hline
\end{tabular}

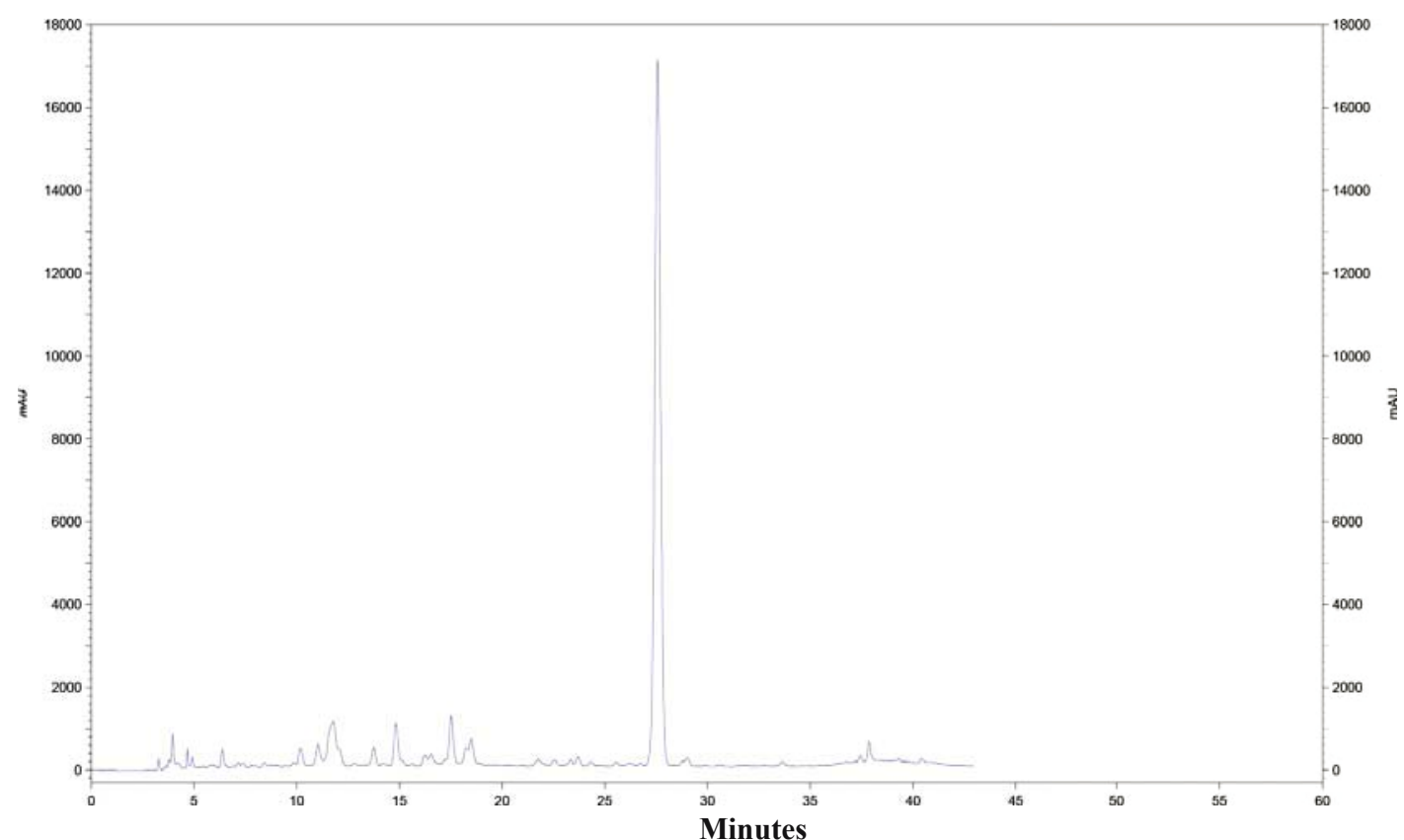

* Peaks are identified as follows: Retention time (RT) $7.0 \mathrm{~min}$ - neochlorogenic acid; RT 7.8 min - 3,4-dihydroxy-benzoic acid; RT $9.8 \mathrm{~min}$ - chlorogenic acid; RT $10.2 \mathrm{~min}$ - catechin; RT $12.7 \mathrm{~min}$ - vanillic acid; RT $13.7 \mathrm{~min}$ - caffeic acid; RT 14.9 min - epicatechin; RT 20.8 min - p-coumaric acid; RT 23.8 min - ferulic acid; RT $24.1 \mathrm{~min}$ - rutin; RT $25.2 \mathrm{~min}$ - ellagic acid; RT 26.2 min - quercetin-3-glicoside; RT $27.5 \mathrm{~min}$ - procyanidin oligomers; RT $30.3 \mathrm{~min}$ - naringin; RT $35.2 \mathrm{~min}$ - myrecetin; RT 40.4 min - quercetin; RT 43.6 min - kaempferol. 
Table 2. Contents of organic acids in Chaenomeles maulei fruit juice

\begin{tabular}{ll}
\hline Organic acid & Content $\mathbf{( m g / 1 0 0 ~} \mathbf{~ m})$ \\
\hline Malic acid & 3647.0 \\
\hline Quinic acid & 1034.0 \\
\hline Citric acid & 51.0 \\
\hline Shikimic acid & 30.0 \\
\hline Ascorbic acid & 22.0 \\
\hline Oxalic acid & 17.0 \\
\hline
\end{tabular}

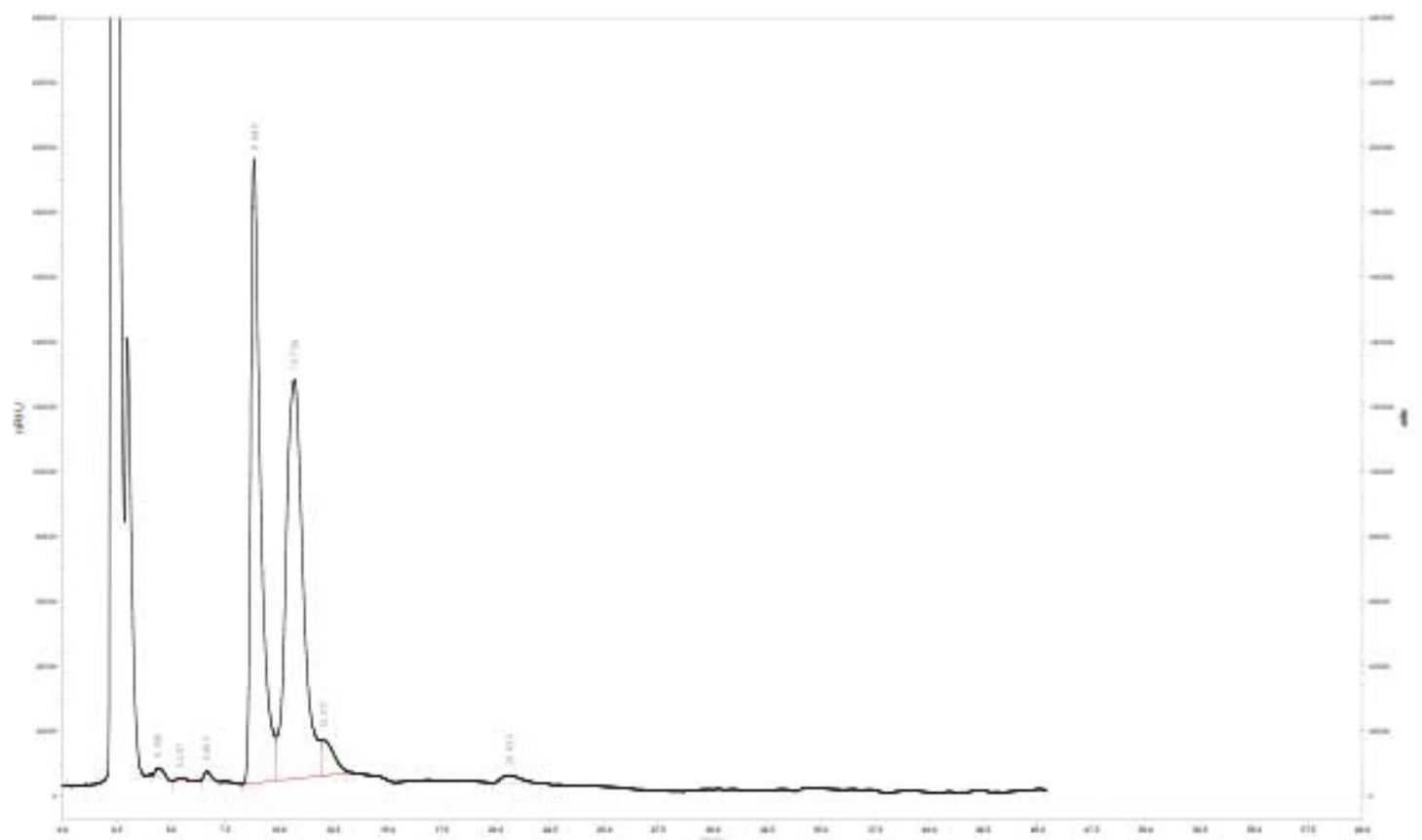

* Peaks are identified as follows: Retention time (RT) 4.4 min - rhamnose; RT 5.4 min - xylose; RT 6.7 min - arabinose; RT $8.9 \mathrm{~min}$ - fructose; RT $10.7 \mathrm{~min}$ - glucose; RT $12.0 \mathrm{~min}$ - galactose; RT $20.8 \mathrm{~min}$ - sucrose.

Figure 2. HPLC chromatogram of sugars in CMFJ

Table 3. Carbohydrate content of Chaenomeles maulei fruit juice

\begin{tabular}{ll}
\hline Carbohydrate & Content $\mathbf{( m g / 1 0 0 ~} \mathbf{~ m})$ \\
\hline Glucose & 1713.0 \\
\hline Fructose & 1237.0 \\
\hline Galactose & 320.0 \\
\hline Sucrose & 189.0 \\
\hline Xylose & 35.0 \\
\hline Rhamnose & 18.0 \\
\hline Arabinose & 8.0 \\
\hline Unidentified disaccharide & 2.7 \\
\hline Polysaccharides & not detected \\
\hline
\end{tabular}

\section{ORAC and HORAC of CMFJ}

The results of the ORAC and HORAC assays showed very high values. They are presented in Table 4.

Table 4. Oxygen radical absorbance capacity (ORAC) and hydroxyl radical averting capacity (HORAC) of Chaenomeles maulei fruit juice; Trolox equivalents (TE), gallic acid equivalents (GAE)

\begin{tabular}{ll}
\hline Assay & Result \\
\hline ORAC & $84401.4 \pm 1934.2 \mu \mathrm{mol} \mathrm{TE} / 1$ \\
\hline HORAC & $18167.8 \pm 938.8 \mu \mathrm{mol} \mathrm{GAE} / 1$ \\
\hline
\end{tabular}




\section{Discussion}

Because of their high acidity and tough pulp, the fruit of Chaenomeles maulei are not suitable for direct consumption but might be a valuable source of bioactive substances.

The current investigation of the chemical composition of CMFJ demonstrated an extremely high amount of phenolic compounds. The total phenolic content was $890 \mathrm{mg}$ GAE/100 $\mathrm{ml}$. For comparison, the content of phenolic substances in Aronia melanocarpa fruit juice ranged from 546.1 to $665.2 \mathrm{mg} \mathrm{GAE} / 100 \mathrm{ml}$ [16]. Literature data show that the content of phenolic compounds measured in orange juice was $75.5 \mathrm{mg} / 100 \mathrm{ml}$, in grapefruit juice 53.5 $\mathrm{mg} / 100 \mathrm{ml}$, in pineapple juice $35.8 \mathrm{mg} / 100$ $\mathrm{ml}$, in apple juice $33.9 \mathrm{mg} / 100 \mathrm{ml}$ [17]. The high content of phenolic substances is an essential property of CMFJ as the total phenolic content of fruit juices correlates with their antioxidant activity [18]. Polyphenols have been demonstrated to act as antioxidants [19] and to affect intracellular signaling molecules [20]. As a result, plant products rich in polyphenols have shown protective effects in experimental models of organ damage and toxicity [21-25] as well as therapeutic effects in inflammation and cancer $[26,27]$. Due to their ability to improve memory polyphenols are possible new approaches to treat neurodegenerative diseases [28-30]. They also possess antimicrobial, antiviral and antifungal activities [31]. The high content of polyphenols in $\mathrm{CMFJ}$ is a prerequisite for future investigation of its health benefits.

The review of the literature shows that the current investigation presents in full detail the polyphenolic profile of a chaenomeles juice. The most abundant phenolic acid was vanillic acid. It probably contributes to the pleasant flavor of the juice. From the flavonoids, the highest was the content of epicatechin and catechin. In the analyzed CMFJ sample, six organic acids were identified, and the highest was the amount of malic acid. Hellín et al. (2003) [32] established three organic acids in chaenomeles juices: malic acid, quinic acid, and succinic acid. The highest was the content of malic acid, followed by quinic acid. The very high content of organic acids accounts for the acidity of CMFJ. The $\mathrm{pH}$ of the investigated CMFJ sample was 2.58. The high acidity makes CMFJ undrinkable if not sweetened. At the same time, it is suitable as a natural acidifying agent in foods like lemon juice. Malic acid is currently used in food industry as an acidifying additive (E-296).

The content of HPLC-detected ascorbic acid in CMFJ was $22 \mathrm{mg} / 100 \mathrm{ml}$. Hellín et al. (2003) [33] reported a high amount of vitamin $\mathrm{C}$ in chaenomeles juices: $45-109 \mathrm{mg}$ as ascorbic acid/100 ml. These authors did not detect ascorbic acid by HPLC analysis, suggesting that all vitamin $\mathrm{C}$ was in the dehydroascorbic acid form. In the current investigation, the ascorbic acid content was identified by HPLC. For comparison, the content of vitamin $\mathrm{C}$ in lemon juice was reported to be $50.82 \mathrm{mg} / 100 \mathrm{ml}$, in orange juice $39.25 \mathrm{mg} / 100 \mathrm{ml}$ and in grapefruit juice $35.23 \mathrm{mg} / 100 \mathrm{ml}$ [34].

Amongst the seven monosaccharides detected in CMFJ, the highest was the content of glucose $(1.713 \mathrm{~g} / 100 \mathrm{ml})$ followed by fructose $(1.237$ $\mathrm{g} / 100 \mathrm{ml})$. Other investigations of chaenomeles juices demonstrated that the highest content was that of fructose $(0.73-2.29 \mathrm{~g} / 100 \mathrm{ml})$, followed by glucose $(0.31-1.07 \mathrm{~g} / 100 \mathrm{ml})$ [33]. For comparison, in lemon juice and orange juice, the glucose content was respectively $0.5 \mathrm{~g} / 100$ $\mathrm{ml}$ and $2.4 \mathrm{~g} / 100 \mathrm{ml}$, and the respective fructose content was $0.9 \mathrm{~g} / 100 \mathrm{ml}$ and $2.4 \mathrm{~g} / 100 \mathrm{ml}$ [35].

The antioxidant activity of CMFJ was investigated by the ORAC and HORAC assays. The ORAC assay measures the ability of an antioxidant to neutralize peroxyl radicals that have proven to be of highest physiological significance. The HORAC assay measures the ability of an antioxidant to prevent hydroxyl radical formation. Since the hydroxyl radicals are the most reactive forms of oxygen, it is of particular importance to assess the ability of an antioxidant or a sample to prevent their formation. The ORAC of CMFJ was $84401.4 \pm 1934.2 \mu \mathrm{mol}$ TE/l, and the HORAC value was $18167.8 \pm 938.8$ $\mu \mathrm{mol}$ GAE/l. The high antioxidant activity of CMFJ might be attributed to its high content of phenolic substances and vitamin C. For comparison, the ORAC of Aronia melanocarpa fruit juice ranged from 52045 to $74045 \mu \mathrm{mol}$ $\mathrm{TE} / \mathrm{l}$, and the HORAC ranged from 30560 to $51661 \mu \mathrm{mol}$ GAE/1 [16]. Thus, both juices showed very high antioxidant activities in vitro, but due to their different polyphenol profile, the 
ORAC was higher for CMFJ while the HORAC was higher for Aronia melanocarpa fruit juice.

\section{Conclusions}

The investigation of the chemical composition of Chaenomeles maulei fruit juice showed a very high content of phenolic compounds, the predominant of which were procyanidins, phenolic acids, and flavonoids. The sour taste of the juice, attributed to the high content of organic acids, might prove useful in the food industry. The juice showed a very high antioxidant activity assessed by the ORAC and HORAC assays. The highly active ingredients of the juice possessing not only antioxidant but also many other beneficial activities make the juice a promising tool for future research.

\section{Acknowledgements}

This research received no specific grant from any funding agency in the public, commercial, or not-for-profit sectors.

\section{Conflict of Interest Statement}

The Authors declare that there is no conflict of interest.

\section{References}

1. Phipps JB, Robertson KR, Smith PG, Rohrer JR. A checklist of the subfamily Maloideae (Rosaceae). Can J Bot. 1990;68:2209-69.

2. Weber C. Cultivars in the genus Chaenomeles. Arnoldia. 1963;23(3):17-75.

3. Rumpunen K. Chaenomeles: potential new fruit crop for northern Europe. In: Janick J, Whipkey A, editors. Trends in new crops and new uses. Alexandria: ASHA Press; 2002.

4. Lesinska E. Characteristics of sugars and acids in the fruits of East Asian quince. Die Nahrung. 1987;31(7):763-5.

5. Lesinska, E. Some volatile and non volatile components of the dwarf quince (Chaenomeles japonica). J Food Sci. 1988;53(3):854-6.

6. Miao J, Li X, Zhao C, Gao X, Wang Y, Gao W. Active compounds, antioxidant activity and $\alpha$-glucosidase inhibitory activity of different varieties of Chaenomeles fruits. Food Chem. 2018;248:330-9.

7. Ruisa S. Studies on Japanese quince (Chaenomeles japonica) in Latvia. In: Report 1992-1994. Sweden: University of Agricultural Sciences; 1996. p.204-6.
8. Essawi T, Srour M. Screening of some Palestinian medicinal plants for antibacterial activity. J Ethnopharmacol. 2000;70(3):343-9.

9. Dai M, Wei W, Shen YX, Zheng YQ. Glucosides of Chaenomeles speciosa remit rat adjuvant arthritis by inhibiting synoviocyte activities. Acta Pharmacol Sin. 2003;24(11):1161-6.

10. Owczarek K, Hrabec E, Fichna J, Sosnowska D, Koziołkiewicz M, Szymański J et al. Flavanols from Japanese quince (Chaenomeles japonica) fruit suppress expression of cyclooxygenase-2, metalloproteinase-9, and nuclear factor-kappa B in human colon cancer cells. Acta Biochim Pol. 2017;64(3):567-76.

11. Singleton VL, Rossi JA. Colorimetry of total phenolics with phosphomolybdicphosphotungstic acid reagents. Am J Enol Vitic. 1965; 16:144-58.

12. Sarneckis CJ, Dambergs RG, Jones P, Mercurio M, Herderich MJ, Smith PA. Quantification of condensed tannins by precipitation with methyl cellulose: development and validation of an optimized tool for grape and wine analysis. Aust J Grape Wine Res. 2006;12(1):39-49.

13. Ou B, Hampsch-Woodill M, Prior RL. Development and validation of an improved oxygen radical absorbance capacity assay using fluorescein as the fluorescence probe. J Agric Food Chem. 2001;49(10):4619-26.

14. Denev P, Ciz M, Ambrozova G, Lojek A, Yanakieva I, Kratchanova M. Solid phase extraction of berries' anthocyanins and evaluation of their antioxidative properties. Food Chem. 2010;123(4):1055-61.

15. Ou B, Hampsch-Woodill M, Flanagan J, Deemer EK, Prior RL, Huang D. Novel fluorometric assay for hydroxyl radical prevention capacity using fluorescein as the probe. J Agric Food Chem. 2002;50(10):2772-7.

16. Valcheva-Kuzmanova S, Denev P, Krachanova M, Surleva A, Belcheva A. [Composition and antioxidant activity of Aronia melanocarpa fruit juice]. Varna Medical Forum. 2014;3(1):15-20. Bulgarian.

17. Gardner PT, White TAC, McPhail DB, Duthie GG. The relative contributions of vitamin $\mathrm{C}$, carotenoids and phenolics to the antioxidant potential of fruit juices. Food Chem. 2000;68(4):471-4.

18. Valcheva-Kuzmanova S, Ivanova D, Belcheva A. Total phenolic content and in vitro antioxidant activity of fruit juices from Aronia melanocarpa, Punica granatum and Rubus caesius. Bull Med Inst Mehrabyan. 2006;2:5-9.

19. Lotito SB, Frei B. Consumption of flavonoid-rich foods and increased plasma antioxidant capacity in humans: cause, consequence, or epiphenomenon? Free Radic Biol Med. 2006;41(12):1727-46.

20. Williams RJ, Spencer JP, Rice-Evans C. Flavonoids: Antioxidants or signalling molecules? Free Radic Biol Med. 2004;36(7):838-49. 
21. Valcheva-Kuzmanova S, Marazova K, Krasnaliev I, Galunska B, Borisova P, Belcheva A Effect of Aronia melanocarpa fruit juice on indomethacininduced gastric mucosal damage and oxidative stress in rats. Exp Toxicol Pathol. 2005;56(6):38592.

22. Valcheva-Kuzmanova SV, Popova PB, Galunska BT, Belcheva A. Protective effect of Aronia melanocarpa fruit juice pretreatment in a model of carbon tetrachloride-induced hepatotoxicity in rats. Folia Med. 2006;48(2):57-62.

23. Valcheva-Kuzmanova S, Kuzmanov K, Tancheva S, Belcheva A. Hypoglycemic and hypolipidemic effects of Aronia melanocarpa fruit juice in streptozotocin-induced diabetic rats. Meth Find Exp Clin Pharmacol. 2007;29(2):101-5.

24. Valcheva-Kuzmanova S, Stavreva G, Dancheva V, Terziev L, Dimitrova A, Shopova V. Effect of Aronia melanocarpa fruit juice on the activity of antioxidant enzymes in a rat model of amiodaroneinduced pneumotoxicity. J Biomed Clin Res. 2012;5(2):97-103.

25. Valcheva-Kuzmanova S. Comparative study of the protective effect of Aronia melanocarpa fruit juice and quercetin in a model of paracetamolinduced hepatotoxicity in rats. J Biomed Clin Res. 2015;8(2):118-23.

26. Ramos S. Cancer chemoprevention and chemotherapy: dietary polyphenols and signaling pathways. Mol Nutr Food Res. 2008;52(5):50726.

27. Ferrazzano GF, Amato I, Inquenito A, Zarreli A, Pinto G, Pollio A. Plant polyphenols and their anti-cariogenic properties: a review. Molecules. 2011;16(2):1486-507.
28. Dai Q, Borenstein AR, Wu Y, Jackson JC, Larson EB. Fruit and vegetable juices and Alzheimer's disease: the Kame project. Ame J Med. 2006;119(9):751-9.

29. Valcheva-Kuzmanova S, Eftimov M, Belcheva I, Tashev R, Belcheva S. Effect of Aronia melanocarpa fruit juice on learning and memory in the two-way active avoidance task in rats. J Biomed Clin Res. 2013;6(1):18-23.

30. Valcheva-Kuzmanova S, Eftimov MT, Tashev RE, Belcheva IR, Belcheva SP. Memory effects of Aronia melanocarpa fruit juice in a passive avoidance test in rats. Folia Med. 2014;56(3):199203.

31. Valcheva-Kuzmanova S, Russev V, Bojkova K, Belcheva A. Study of natural Aronia melanocarpa fruit juice for antibacterial and antiviral activity. Scr Sci Med. 2002;35:21-23.

32. Daglia M. Polyphenols as antimicrobial agents. Curr Opin Biotechnol. 2012;23(2):174-81.

33. Hellín P, Vila R, Jordán MJ, Laencina J, Rumpunen K, Ros JM. Characteristics and composition of Chaenomeles fruit juice. In: Rumpunen $\mathrm{K}$, editor. Japanese quince - potential fruit crop for northern Europe.. Sweden: University of Agricultural Sciences; 2003. p.127-39.

34. Pisoschi AM, Pop A, Negulescu GP, Pisoschi A. Determination of ascorbic acid content of some fruit juices and wine by voltammetry performed at pt and carbon paste electrodes. Molecules; 2011;16(2):1349-65.

35. Belitz HD, Grosch W, Schieberle P. Carbohydrates. In: Food Chemistry. Burghagen $M$, editor: Heidelberg: Springer;2004. p.245-341. 